\title{
Behavioral plasticity is not significantly associated with head volume in a wild Chestnut Thrush (Turdus rubrocanus) population
}

Qingshan Zhao ${ }^{1,2}$ and Yuehua Sun ${ }^{1 *}$

\begin{abstract}
Background: The drivers of intraspecific variation in behavioral plasticity are poorly known. A widely held hypothesis is that brain size is positively correlated with behavioral plasticity.

Methods: A total of 71 Chestnut Thrushes (Turdus rubrocanus) were caught in the wild population. We quantified behavior plasticity of activity of individuals measured in the same cage across two contexts (common and with a novel object stimulation), using a random regression analysis. We then investigated whether head volume (a proxy for brain size) was associated with behavioral plasticity in activity level using Spearman rank-order correlation.

Results: We found no significant evidence that activity plasticity was associated with relative head volume. There was no sex difference in head volume or in variance in head volume.

Conclusions: We speculate that the absence of an association between brain volume and activity behavior plasticity may result from the inaccuracy of using external skull measurements to estimate brain size, or from a particular part of the brain being responsible for plasticity in activity level.
\end{abstract}

Keywords: Activity, Behavioral plasticity, Chestnut Thrush, Head volume

\section{Background}

Behavioral plasticity is the ability of an animal to alter its behavior in response to changes in the environment, and the evolutionary causes and consequences of behavioral plasticity has received much attention in the past four decades (Dingemanse et al. 2010; Betini and Norris 2012). Snell-Rood (2013) defined two major forms of behavioral plasticity: developmental and activational. Developmental behavioral plasticity is analogous to the traditional definition of phenotypic plasticity: environmental conditions at a specific life history phase drive individual behavior into an irreversible developmental trajectory, and result in a fixed behavioral phenotype in adulthood (Piersma and Drent 2003; Dingemanse and Wolf 2013). Activational behavioral plasticity is short-term environmental effects on behavior: individuals express different

\footnotetext{
*Correspondence: sunyh@ioz.ac.cn

${ }^{1}$ Key Laboratory of Animal Ecology and Conservation Biology, Institute of Zoology, Chinese Academy of Sciences, Beijing 100101, China Full list of author information is available at the end of the article
}

behaviors based on current different contexts or environments, regardless of the past environment (Dingemanse and Wolf 2013; Snell-Rood 2013). Differential activation of an underlying neural network may result in plasticity (Snell-Rood 2013). An increase in behavioral plasticity should correspond to an increase in sensory input and neuron number and ultimately overall brain size (SnellRood 2013).

The relative brain size of birds is comparable to that of mammals, but varies greatly among taxa (Winkler et al. 2004; Day et al. 2005). Studies have revealed that brain size of bird is correlated with measures of behavioral flexibility such as invasion success (Sol and Lefebvre 2000; Sol et al. 2002; Møller and Erritzøe 2015), life history traits (Iwaniuk and Nelson 2003), feeding innovation (Lefebvre et al. 2004), food hoarding (Garamszegi and Eens 2004), migration (Shultz et al. 2005), and escape strategy (Samia et al. 2015). Compared with a large body of studies that addressed interspecific variation in brain size, studies of brain size at the intraspecific level, even 
intra-population level, have only recently started (Gonda et al. 2013). Although intraspecific variation in brain size is smaller than interspecific variation (Gonda et al. 2013), there also exists an association between brain size and behavioral flexibility at the within-population level, including migratory behavior (Møller 2010; Fuchs et al. 2015), food hoarding (Roth and Pravosudov 2009), antipredator behavior (Öst and Jaatinen 2015) and breeding strategies (Jaatinen and Öst 2016). Thus behavioral plasticity should be linked with brain size at the intra-population level (Mery and Burns 2010).

The aim of this study was to test whether variation in behavioral plasticity correlate with brain size in a wild Chestnut Thrush (Turdus rubrocanus) population. Quantification of behavioral plasticity under natural conditions could be a challenge. First, environmental variables may show little variation, and it may be difficult to quantify a given condition experienced by the subject (Lefebvre et al. 2004). Second, conspecifics and heterospecifics in the surroundings can affect the measurement of an individual's behavior (Kluen et al. 2012). Thus it may be better to evaluate individual behaviors in an artificial, standard environment. Therefore, we used a modified simple cage test developed by Kluen et al. (2012) to quantify individual behavioral plasticity of activity. Activity level may be a key trait that links behavior to feeding rate and predation risk (Sih et al. 2004). The response to novel stimuli has been described as a simple mechanism to regulate ecological plasticity (Brown et al. 2013). So we use the change of activity in the presence and absence of the novel object to quantify the behavioral plasticity. Brain size is tightly correlated with head volume, so we use head volume as a proxy for brain size (Møller 2010; Öst and Jaatinen 2015). For reasons discussed above, we predicted that behavioral plasticity is positively correlated with head volume.

\section{Methods}

\section{Study area and subjects}

We conducted this study in April-July 2014 in a farmland landscape at the northern edge of the Lianhuashan Nature Reserve, Gansu Province, Central China $\left(34.67^{\circ} \mathrm{N}\right.$, $103.50^{\circ} \mathrm{E}$ ). In our study area, Chestnut Thrushes start to build nests in late April and clutches are initiated from early May to late June. We used mist nets to catch birds. All birds trapped were weighed (to the nearest $0.1 \mathrm{~g}$ ), measured for tarsus length (to the nearest $0.1 \mathrm{~mm}$ ), wing length (to the nearest $0.1 \mathrm{~mm}$ ), and head size (width, breadth, and height to the nearest $0.01 \mathrm{~mm}$ ), and banded. We estimate head volume as the product of head length (minus beak length), head width, and head height to the nearest $0.01 \mathrm{ml}$ according to Møller (2010). We captured 71 adult birds. And 23 individuals were recaptured.

\section{Simple cage test}

Each bird was tested individually in a standard cage $(50 \mathrm{~cm} \times 36 \mathrm{~cm}$ and $60 \mathrm{~cm}$ high) similar to that described by Kluen et al. (2012) between 0900 and 1600 hours. After a habituation period of $10 \mathrm{~min}$, the experimenter briefly entered his hand in the cage, as if something was hanged from the roof of the cage. After that, we videoed the bird for $5 \mathrm{~min}$, and this is the baseline session. Then, we hung a novel object (a pink plastic pig measuring $6 \mathrm{~cm} \times 5 \mathrm{~cm} \times 10 \mathrm{~cm}$, presumably unknown in this natural environment) from the roof of the cage, and then video-recorded for $5 \mathrm{~min}$ (the test session). To quantify behavioral plasticity, we quantified the activity (5-min records of the number of hops and short flights within and between perches) in these two sessions, respectively. Twenty-three recaptured birds were tested twice in different days (with at least 7-day interval).

\section{Statistical analyses}

The repeatability of head volume measured on different days was calculated using a linear mixed model (LMM) with individual identity (ID) as a random effect. Following recommendations of Nakagawa and Schielzeth (2010), information on individuals with only one measure was retained. We used the function rpt.remlLMM of $\mathrm{R}$ package 'rptR' to calculate repeatability and $p$ values for repeatability derived from log likelihood ratio test (LRT) (Nakagawa and Schielzeth 2010). To calculate relative head volume, the allometric effect needs to be accounted for (Iwaniuk and Nelson 2003). We first ran a linear regression to test whether sex, wing length, tarsus length and body mass were significantly associated with head volume. We found that tarsus length was positively correlated with head volume. Therefore, we calculated the residuals (relative head volume) of a log-log leastsquares linear regression of brain volume against tarsus length (Iwaniuk and Nelson 2003; Sol et al. 2005).

We calculated behavior plasticity of activity of individuals measured in the same cage across two contexts (common and with a novel object stimulation), using a random regression analysis (Nussey et al. 2007; Kluen and Brommer 2013). We used the square-root transformation of activity (to make error distribution approximate normality) as the response variable. As we were mainly interested in the random effects, we considered the slope of the regression line as behavior plasticity when the interaction between ID and context is fitted as a random effect. As fixed effects, sex (female and male), date (where April $17=1$, April $18=2$, etc.), context, and test time (where 12 o'clock noon $=0$, 1 p.m. $=1,11$ a.m. $=-1$, etc.) were included in this model. Given that individuals were tested at different times in their reproductive cycle, and hormone levels 
and the resultant behavior change during the breeding cycle, nest age (day 1 is the day of clutch initiation) was also included as a fixed effect. To calculate repeatability of behavior plasticity, we extracted random slope for first and second test separately, and then we used function rpt.remlLMM to calculate repeatability and relevant LRT P value. Because the second encounter with the pink pig may not contain the same degree of novelty anymore, we use the data of head volume and behavior measured for the first time in the final analysis. To investigate whether there was a significant interaction between ID and context on activity, we compared models with and without a random slope for context using a LRT (Carter et al. 2012). We used model averaging and information theoretic approaches to rank the full model. The small-sample version of the Akaike information criterion (AICc) was used to rank model and parameter averaging was based on the subset $(\mathrm{AICc}<2)$ of all possible models that involve predictor variables (Burnham and Anderson 2002). Function dredge and model.average of 'MuMIn' package (Bartoń 2015) was used to conduct model selection and model averaging, respectively.

All statistical analyses were conducted using R 3.2.3 ( $R$ Core Team 2015). Random regression analysis was fitted using the package 'nlme' (Pinheiro et al. 2015). In cases of multiple related tests, we used the Hochberg's sequential Bonferroni procedure to adjust the significance levels $(p=0.05)$ by using package 'multcomp' (Hochberg 1988; Hothorn et al. 2008).

\section{Results}

Head volume measured on different days for a sample of 23 individuals (male $=7$, female $=16$ ) was highly repeatable $[R(\mathrm{SE})=0.92(0.02)$, CI $[0.86,0.96], p<0.001]$. Head volume was on average $14.20 \mathrm{~mL}, \mathrm{SD}=0.92$, range 12.41-16.42, $\mathrm{CV}=6.47 \%, n=30$ males, and on average $14.28 \mathrm{~mL}, \mathrm{SD}=1.55$, range $11.36-18.99, \mathrm{CV}=10.89 \%$, $n=41$ female. Neither sexual difference in head volume (Welch ANOVA, $F_{1,66.42}=0.70, p=0.79$ ) nor the sexual difference of variances in head volume was significant (Levene's test, $F_{1,69}=0.07, p=0.79$ ). Head volume was not significantly related to body mass or wing length (Table 1). Head volume was positively correlated with tarsus length (Table 1), indicating that individuals with larger body size have larger head volume.

We successfully performed the cage experiment 94 times with 71 birds, 23 recaptured individuals experienced the whole cage test again. Behavioral plasticity measured on different days for a sample of 23 individuals was moderately repeatable $[R(\mathrm{SE})=0.39(0.17), \mathrm{CI}$ [0.002, 0.705], $p=0.04]$. Activity of individual Chestnut Thrushes increased after being introduced to the novel
Table 1 Summary of the linear model of head volume $(\mathrm{mL})$ in relation to sex, body mass, wing length and tarsus length of Chestnut Thrush $(n=71)$

\begin{tabular}{lllll}
\hline Variable & Sum of squares & df & $\boldsymbol{F}$ & $\boldsymbol{p}$ \\
\hline Body mass & 0.11 & 1 & 0.06 & 0.80 \\
Wing length & 0.29 & 1 & 0.17 & 0.68 \\
Sex & 0.02 & 1 & 0.01 & 0.91 \\
Tarsus length & 8.30 & 1 & 4.85 & 0.03 \\
\hline
\end{tabular}

object (Table 2; Fig. 1). Activity was not significantly related to date, time of day, nest age, and sex (Table 2). Individuals responded differently to the novel object. There was a significant interaction between context and ID (Table 2). There was no significant sex difference in head volume (Table 2). Spearman correlation analyses revealed no evidence that activity plasticity was related to relative head volume $\left(r_{\mathrm{S}}=0.05, p=0.72, n=71\right.$, Fig. 2$)$.

Table 2 Model-averaged parameter estimates, unconditional standard errors (SE), $95 \%$ confidence $(95 \% \mathrm{Cl}$ ) and relative importance for factors from supported models predicting activity level of Chestnut Thrush

\begin{tabular}{lcclll}
\hline $\begin{array}{l}\text { Variables in } \\
\text { averaged model }\end{array}$ & Estimate & SE & $\boldsymbol{Z}$ value & $\boldsymbol{p}$ & $\begin{array}{l}\text { Relative } \\
\text { importance }\end{array}$ \\
\hline $\begin{array}{l}\text { Fixed effect } \\
\text { Intercept }\end{array}$ & 2.18 & 0.40 & 5.40 & 0.001 & \\
Context & 3.07 & 0.39 & 7.68 & 0.001 & 1 \\
Sex & -0.38 & 0.50 & 0.75 & 0.45 & 0.5 \\
Nest age & 0.01 & 0.01 & 0.33 & 0.74 & 0.3 \\
Random terms & & & $x^{2}$ & $p$ & \\
Context|bird ID & & & 6.25 & 0.04 & 1 \\
\hline
\end{tabular}

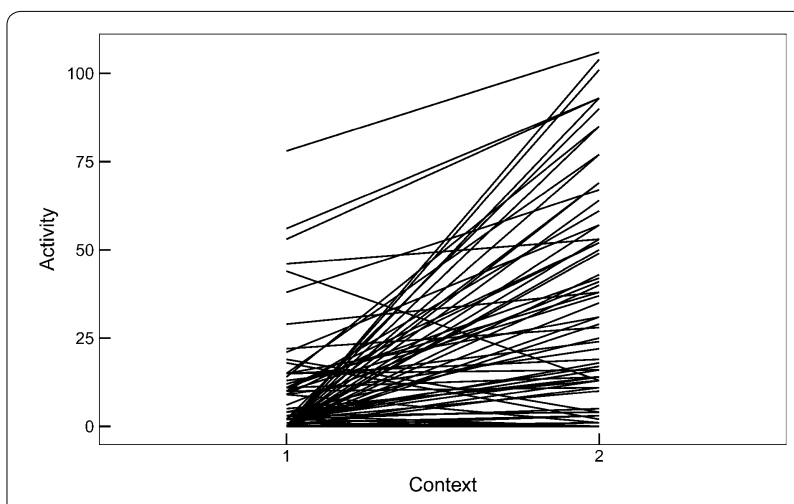

Fig. 1 Individual activity of Chestnut Thrush measured in two contexts (context 1 is a normal environment, context 2 is an environment with a novel object) $(n=71)$ 


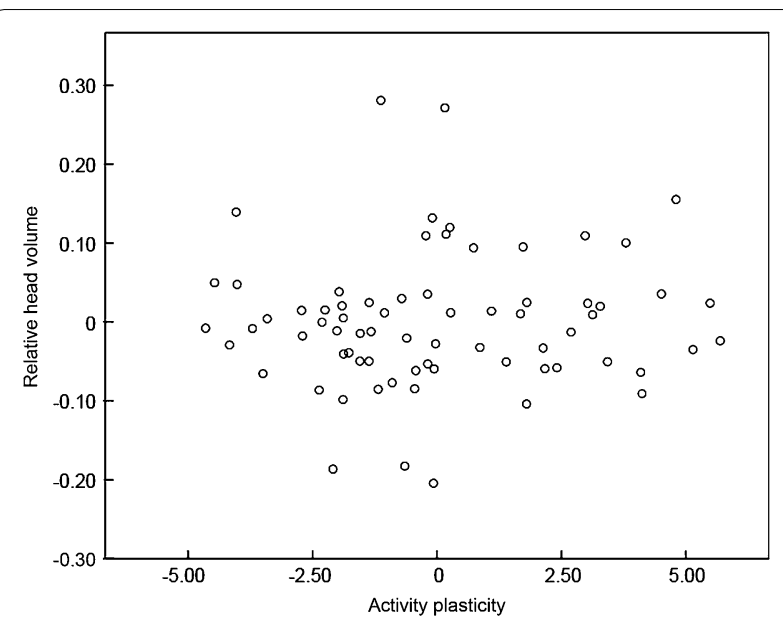

Fig. 2 Relationship between activity plasticity and relative head volume of Chestnut Thrush. Relative head volume was adjusted for tarsus length, while activity plasticity was adjusted for sex, date, time, nest age and context. The relationship was not statistically significant (Pearson $r=0.05, n=71, p=0.72$ )

\section{Discussion}

Despite mounting evidence that brain size is linked to behavioral plasticity (Öst and Jaatinen 2015; Jaatinen and Öst 2016), we found no significant association between plasticity in activity and head volume of Chestnut Thrushes in a wild population. In addition, males and females showed no difference in their plasticity in activity and head volume. Head volume and behavioral plasticity were highly repeatable among captures, suggesting that the measurement is reliable.

There are at least two potential explanations for the lack of association between plasticity of activity and head volume in this population. First, head volume may not be an accurate proxy for brain size for the Chestnut Thrush. We did not verify the hypothetical positive correlation between brain mass and head volume. As in any new field of research, the accuracy of using head volume as a proxy is still controversial (Healy and Rowe 2007; Jaatinen and Öst 2016). Brain size measured using head volume has been validated across species (Iwaniuk and Nelson 2002; Møller et al. 2011). At intraspecific level, the strong positive correlation between head volume and brain mass had been found in Short-tailed Shearwaters (Puffinus tenuirostris) (Iwaniuk and Nelson 2003), Budgerigars (Melopsittacus undulatus) (Iwaniuk and Nelson 2003), and Barn Swallows (Hirundo rustica) (Møller 2010). However, in female Great-tailed Grackles (Quiscalus mexicanus), linear measurements of skull were a poor predictor of head volume from computerized tomography scans (Logan and Palmstrom 2015). It is possible that the external skull measurements are not accurate enough to have the ability to detect the intra-population differences of Chestnut Thrush (Logan and Palmstrom 2015). We must keep in mind that the use of external skull measurements to estimate head volume in a species without proper validation can be premature (Logan and Palmstrom 2015).

Second, it is possible that plasticity in activity is correlated with size of a specific brain part and not overall brain size, even if external skull measurements provide a reliable estimate of brain size. Different behaviors are likely to be under the control of different brain areas (Wingfield 2015). For example, hippocampus volume is linked to food-storing behavior in bird (Croston et al. 2015; Sherry and MacDougall-Shackleton 2015); the size of auditory areas is linked to song learning behavior in bird (Nottebohm 1981; Chakraborty et al. 2015); and the size of the forebrain region is link to social behavior (Lipkind et al. 2002). A recent study reported the absence of correlation between activity during the novel object stimulation after 41 days of environmental enrichment and neurogenesis in the hippocampus and lateral striatum of adult pigeons (Columba livia) (Melleu et al. 2015), suggesting that those two brain areas may not be responsible for variation in activity during exposure to novel objects. Given that innovation frequency is positively correlated with the nidopallium and hyperpallium ventral of the forebrain in birds (Timmermans et al. 2000), it is possible that these two areas of the forebrain affect the activity plasticity in novel contexts.

Cognitive and learning ability may also mediate between brain size and behavioral plasticity. However, using brain size as a valid measure of cognitive ability is still controversial (Butler and Hodos 2005; Kaplan 2015). Brain size predicts cognitive ability in primates (Deaner et al. 2007). However, there is no association between brain weight in relation to body size and intelligence' to date (Healy and Rowe 2007). Cognitive ability may involve just some specific part of the brain. It is better to measure the neural mechanisms rather than the whole brain (Kaplan 2015). The experimental procedure we used could not tell apart the activational and developmental in activity level. To disengage this problem, we require experiments with hand raised birds to fully understand early developmental influences on activity.

Sex differences in brain size may result from sexual selection in many life-history traits of birds such as extra-pair paternity (Garamszegi et al. 2005a), songs complexity (Garamszegi et al. 2005b), and mating system (Garamszegi et al. 2005b). Neither sex difference in head volume nor variance in head volume was found in Chestnut Thrush. Our result is not in line with a study of the Barn Swallow (Møller 2010), in which males have larger head volume than females, while females have greater variance than males (Møller 2010). Møller (2010) 
speculated that the heterogametic sex had greater variability in brain size than the homogametic sex. Our result does not support this suggestion. Surprisingly, we did not find that males have larger brain size than females. According to our field observations, song complexity of male Chestnut Thrush is much higher than female. Our results are not consistent with the prediction that females have smaller brain size in species with large sexual differences in song complexity (Garamszegi et al. 2005b).

\section{Conclusions}

To conclude, this study found no evidence that activity plasticity is significantly associated with relative head volume in chestnut thrushes. We found no significant sex differences in head volume or variance in head volume. These results are surprising given the large body of evidence in the literatures that behavioral plasticity is correlated with brain size.

\section{Authors' contributions}

QZ designed and performed the experiments, completed the analyses, wrote and revised the manuscript; YS conceived, directed, and coordinated this study, helped with writing and revised the manuscript. Both authors read and approved the final manuscript.

\section{Author details}

${ }^{1}$ Key Laboratory of Animal Ecology and Conservation Biology, Institute of Zoology, Chinese Academy of Sciences, Beijing 100101, China. ${ }^{2}$ University of the Chinese Academy of Sciences, Beijing 100049, China.

\section{Acknowledgements}

This research was supported by the National Natural Science Foundation of China (Grant No. 31472012). We thank the staffs of the Lianhuashan Nature Reserve for their invaluable assistance, Yun Fang, Pengfei Liu, Yunbiao Hu, Lijun Chen and Yingqiang Lou for their help in fieldwork. We thank Anders Pape Møller for his help with the English and comments on the manuscript.

\section{Competing interests}

Both authors declare that they have no competing interests.

\section{Ethics statement}

The experiments were conducted under the approval of the Animal Care and Ethics Committee and carried out in accordance with the guidelines for the Use of Animals in Research issued by the Institute of Zoology, Chinese Academy of Sciences.

Received: 26 April 2016 Accepted: 27 July 2016

Published online: 09 August 2016

\section{References}

Bartoń K. MuMIn: multi-model inference. 2015. https://CRAN.R-project.org/ package=MuMIn. Accessed $12 \operatorname{Jan} 2016$.

Betini GS, Norris DR. The relationship between personality and plasticity in tree swallow aggression and the consequences for reproductive success. Anim Behav. 2012;83:137-43.

Brown GE, Ferrari MCO, Elvidge CK, Ramnarine I, Chivers DP. Phenotypically plastic neophobia: a response to variable predation risk. Proc R Soc B. 2013;280:20122712.

Burnham KP, Anderson DR. Model selection and multi-model inference: a practical information-theoretic approach. Berlin: Springer; 2002.

Butler AB, Hodos W. Comparative vertebrate neuroanatomy: evolution and adaptation. 2nd ed. Hoboken: Wiley; 2005.
Carter A, Goldizen A, Heinsohn R. Personality and plasticity: temporal behavioral reaction norms in a lizard, the namibian rock agama. Anim Behav. 2012:84:471-7.

Chakraborty M, Walløe S, Nedergaard S, Fridel EE, Dabelsteen T, Pakkenberg B, Bertelsen MF, Dorrestein GM, Brauth SE, Durand SE, Jarvis ED. Core and shell song systems unique to the parrot brain. PLoS One. 2015;10:e0118496.

Croston R, Branch CL, Kozlovsky DY, Roth TC, LaDage LD, Freas CA, Pravosudov W. Potential mechanisms driving population variation in spatial memory and the hippocampus in food-caching chickadees. Integr Comp Biol. 2015:55:354

Day LB, Westcott DA, Olster DH. Evolution of bower complexity and cerebellum size in bowerbirds. Brain Behav Evol. 2005;66:62-72.

Deaner RO, Isler K, Burkart J, vanSchaik C. Overall brain size, and not encephalization quotient, best preducts cognitive ability across non-human primates. Brain Behav Evol. 2007;70:115-24.

Dingemanse NJ, Wolf M. Between-individual differences in behavioural plasticity within populations: causes and consequences. Anim Behav. 2013;85:1031-9.

Dingemanse NJ, Kazem AJN, Réale D, Wright J. Behavioural reaction norms: animal personality meets individual plasticity. Trends Ecol Evol. 2010;25:81-9.

Fuchs R, Bingman VP, Ross JD, Bernroider G. Brain contrasts between migratory and nonmigratory north American lark sparrows (Chondestes grammacus). NeuroReport. 2015;26:1011-6.

Garamszegi LZ, Eens M. The evolution of hippocampus volume and brain size in relation to food hoarding in birds. Ecol Lett. 2004;7:1216-24.

Garamszegi LZ, Eens M, Erritzøe J, Møller AP. Sperm competition and sexually size dimorphic brains in birds. Proc Roy Soc B Biol Sci. 2005a;272:159-66.

Garamszegi LZ, Eens M, Erritzøe J, Møller AP. Sexually size dimorphic brains and song complexity in passerine birds. Behav Ecol. 2005b;16:335-45.

Gonda A, Herczeg G, Merilä J. Evolutionary ecology of intraspecific brain size variation: a review. Ecol Evol. 2013:3:2751-64.

Healy SD, Rowe C. A critique of comparative studies of brain size. Proc R Soc B Biol Sci. 2007;274:453-64.

Hochberg Y. A sharper Bonferroni procedure for multiple tests of significance. Biometrika. 1988;75:800-2.

Hothorn T, Bretz F, Westfall P. Simultaneous inference in general parametric models. Biom J. 2008;50:346-63.

Iwaniuk AN, Nelson JE. Can endocranial volume be used as an estimate of brain size in birds? Can J Zool. 2002;80:16-23.

Iwaniuk AN, Nelson JE. Developmental differences are correlated with relative brain size in birds: a comparative analysis. Can J Zool. 2003;81:1913-28.

Jaatinen K, Öst M. Brain size-related breeding strategies in a seabird. Oecologia. 2016;180:67-76

Kaplan G. Bird minds: cognition and behaviour of Australian native birds. Clyton: CSIRO Publishing; 2015.

Kluen E, Brommer JE. Context-specific repeatability of personality traits in a wild bird: a reaction-norm perspective. Behav Ecol. 2013;24:650-8.

Kluen E, Kuhn S, Kempenaers B, Brommer JE. A simple cage test captures intrinsic differences in aspects of personality across individuals in a passerine bird. Anim Behav. 2012;84:279-87.

Lefebvre L, Reader SM, Sol D. Brains, innovations and evolution in birds and primates. Brain Behav Evol. 2004;63:233-46.

Lipkind D, Nottebohm F, Rado R, Barnea A. Social change affects the survival of new neurons in the forebrain of adult songbirds. Behav Brain Res. 2002;133:31-43.

Logan CJ, Palmstrom CR. Can endocranial volume be estimated accurately from external skull measurements in great-tailed grackles (Quiscalus mexicanus)? PeerJ. 2015;3:e1000.

Melleu FF, Pinheiro MV, Lino-de-Oliveira C, Marino-Neto J. Defensive behaviors and prosencephalic neurogenesis in pigeons (Columba livia) are affected by environmental enrichment in adulthood. Brain Struct Funct. 2015;221:2287-301

Mery F, Burns JG. Behavioural plasticity: an interaction between evolution and experience. Evol Ecol. 2010:24:571-83.

Møller AP. Brain size, head size and behaviour of a passerine bird. J Evol Biol. 2010;23:625-35.

Møller AP, Erritzøe J. Brain size and urbanization in birds. Avian Res. 2015;6:8.

Møller AP, Bonisoli-Alquati A, Rudolfsen G, Mousseau TA. Chernobyl birds have smaller brains. PLoS One. 2011;6:e16862. 
Nakagawa S, Schielzeth H. Repeatability for Gaussian and non-Gaussian data: a practical guide for biologists. Biol Rev. 2010;85:935-56.

Nottebohm F. A brain for all seasons: cyclical anatomical changes in song control nuclei of the canary brain. Science. 1981;214:1368-70.

Nussey DH, Wilson AJ, Brommer JE. The evolutionary ecology of individual phenotypic plasticity in wild populations. J Evol Biol. 2007;20:831-44.

Öst M, Jaatinen K. Smart and safe? Antipredator behavior and breeding success are related to head size in a wild bird. Behav Ecol. 2015;26:1371-8.

Piersma T, Drent J. Phenotypic flexibility and the evolution of organismal design. Trends Ecol Evol. 2003;18:228-33.

Pinheiro J, Bates D, DebRoy S, Sarkar D, R Core Team. nlme: linear and nonlinear mixed effects models. 2015. http://CRAN.R-project.org/ package $=$ nlme. Accessed 21 Jan 2016

R Core Team. R: A language and environment for statistical computing. Vienna, Austria. 2015. https://www.R-project.org/.

Roth TC, Pravosudov V. Hippocampal volumes and neuron numbers increase along a gradient of environmental harshness: a large-scale comparison. Proc R Soc Lond B Biol. 2009;276:401-5.

Samia DSM, Pape Møller A, Blumstein DT. Brain size as a driver of avian escape strategy. Sci Rep UK. 2015;5:11913.

Sherry DF, MacDougall-Shackleton SA. Seasonal change in the avian hippocampus. Front Neuroendocrinol. 2015;37:158-67.
Shultz S, Bradbury RB, Evans KL, Gregory RD, Blackburn TM. Brain size and resource specialization predict long-term population trends in British birds. Proc R Soc Lond B Biol Sci. 2005;272:2305-11.

Sih A, Bell AM, Johnson JC, Ziemba RE. Behavioral syndromes: an integrative overview. Q Rev Biol. 2004;79:241-77.

Snell-Rood EC. An overview of the evolutionary causes and consequences of behavioural plasticity. Anim Behav. 2013;85:1004-11.

Sol D, Lefebvre L. Behavioural flexibility predicts invasion success in birds introduced to New Zealand. Oikos. 2000;90:599-605.

Sol D, Timmermans S, Lefebvre L. Behavioural flexibility and invasion success in birds. Anim Behav. 2002:63:495-502.

Sol D, Duncan RP, Blackburn TM, Cassey P, Lefebvre L. Big brains, enhanced cognition, and response of birds to novel environments. Proc Natl Acad Sci USA. 2005;102:5460-5.

Timmermans S, Lefebvre L, Boire D, Basu P. Relative size of the hyperstriatum ventrale is the best predictor of feeding innovation rate in birds. Brain Behav Evol. 2000;56:196-203.

Wingfield JC. Coping with change: a framework for environmental signals and how neuroendocrine pathways might respond. Front Neuroendocrinol. 2015:37:89-96.

Winkler H, Leisler B, Bernroider G. Ecological constraints on the evolution of avian brains. J Ornithol. 2004;145:238-44.

\section{Submit your next manuscript to BioMed Central and we will help you at every step:}

- We accept pre-submission inquiries

- Our selector tool helps you to find the most relevant journal

- We provide round the clock customer support

- Convenient online submission

- Thorough peer review

- Inclusion in PubMed and all major indexing services

- Maximum visibility for your research

Submit your manuscript at www.biomedcentral.com/submit

BioMed Central 